\title{
ESCOLA DE PAIS: RELATÓRIO
}

\section{SCHOOL FOR PARENTS: A REPORT}

\author{
Vera Lucia G. Pereira Lima (Coord.) ${ }^{1}$ \\ Ana Lucia L. Araújo \\ Graciela Pagliaro \\ José Maria Arruda \\ Nora Z. Ribeiro Campos
}

LIMA, V .L. G. P.; ARAUJO, A. L. L.; PAGLIARO, G.; ARRUDA, J. M.; CAMPOS, N. Z. R. Escola de pais: Relatório. Rev. Bras. Cresc. Desenv. Hum., S. Paulo, 11(2), 2001.

Resumo: De acordo com o previsto pelo Estatuto da Criança e do Adolescente - ECA em seu art. 129, parágr. ^lv, cap. V, o qual afirma que são medidas aplicáveis aos pais ou responsável o "encaminhamento a cursos ou programas de orie^lt^lação", a I a Vara da Infancia e Juventude do Rio de Janeiro criou o Projeto "Escola de Pais", visando a reintegração familiar de crianças e adolescentes que vivem em situações de risco social, por meio de ação sócio-educacional junto aos pais. Desde 1998 foram realizadas 9 Escolas de Pais, cada urna delas constituída de cerca de 8 encontros em sua primeira fase, quando são trabalhados temas relacionados à educação, saúde e cidadania, constituindo-se numa oportunidade para garantir direitos e estabelecer obrigações na relação pais e filhos. As famílias recebem bolsas de alimentos of erecidas pela Fundação da Infància e Adolescência (FIA), vales transporte, apoio para manter seus filhos em escolas ou creches da comunidade e do Juizado, orientação de assistentes sociais e psicólogas, e outros benefícios, graças a parcerias estabelecidas com instituições, organizações e empresas, incluindo o setor privado. Após essa fase, os participantes são acompanhados por 12 meses pelo programa Família Solidária, subsidiado por pessoas que apadrinham uma das famílias com a contribuição de I salário mínimo mensal. Outra forma de reinserção social é o apoio of erecido na busca de oportunidades de geração de renda para as famílias, que inclui a integração à Cooperativa da Escola de Pais, em funcionamento. As Secretarias de Ação Social e Desenvolvimento Social de Estado e Município, respectivamente, assim como os Conselhos Tutelares estão envolvidos no programa, garantindo a continuidade do trabalho além dos limites do Juizado e o acompanhamento das famílias em seus locais de moradia.

Palavras-chave: Escola de Pais; Vara da Infancia e Adolescência; pais infratores; Estatuto da Criança e do Adolescente.

\section{APRESENTAÇÃO}

O presente Relatório foi elaborado pela equipe de profissionais que integra a Representação do Brasil junto à Oficina Latino-Americana da União Internacional de Promoção da Saúde e Educação para a Saúde (UIPES/ORLA/ Sub-Região Brasil), convidadapara acompanhar as ativi- dades da $8{ }^{\wedge}$ a Escola de Pais. Essa participação confirmou a coerência da proposta com princípios e estratégias de promoção da saúde propostas pelas Conferências Internacionais de Promoção da Saúde patrocinadas pela O MS (Ottawa, 1986, Adelaide, 1988; Sundswall, 1991; Jacarta, 1997; México, 2000), tais como a busca da inclusão social e da equidade, a construção e o exercí-

1 Representação da Sub-Região Brasil junto à Oficina Regional Latino-Americana da União internacional de Promoção da Saúde e Educação para a Saúde - UIPES/ORLA-BR. E-mail: vllima@openlink.com.br 
cio da cidadania, e, ainda, o enfoque multidisciplinar, a intersetorialidade, a formação de parcerias, a preocupação em desenvolver ações resolutivas e sustentáveis.

O Projeto Escola de Pais da la Vara da Infância e Juventude do Rio de Janeiro, amparado no ECA - parágrafo 1, art. 19, que trata do direito à convivência familiar e comunitária, e parágrafo 4 , art. 129, que propõe medidas pertinentes aos pais ou responsável - baseia-se no reconhecimento da importância da criação dos filhos menores no seio da família, e tem como objetivo promover o fortalecimento dos vinculos afetivos nas familias de crianças e adolescentes que se encontram em situação de risco pessoal e/ou social ( $1^{\text {a }}$ Vara da Infância e Juventude do Rio de Janeiro, Núcleo de Escola de Pais).

O Núcleo da Escola de Pais (NEP) da $1^{\mathrm{a}}$ Vara da Infância e Juventude do Rio de Janeiro, realizando a $8^{\text {a }}$ Escola de Pais, teve a coordenação de Regina ZANDONADI e Regina ANDREIOLO, o apoio da Equipe do NEP/1 ${ }^{\mathrm{a}}$ Vara da Infância e Juventude, ocorrendo no horário de $5^{\mathrm{a}}$ feira de 9:00 às 11:30 horas, no período de 29/3/2001 a 24/05/01 - no auditório da la Vara da Infância e Juventude, Praça 11 de Junho, 403/3 andar - Cidade Nova, Rio de Janeiro, RJ, Tel.: 2293-8497 ramais: 246/247.

O programa do NEP consistiu das seguintes atividades ${ }^{2}$ :

- Aprendendo com música: Regina de SÁ;

- O que sabemos fazer com as mãos: Marta NIKLAUS;

- Conhecendo nossos filhos: Vania PIRES; Alcool e drogas: Margarida CONSTANCIO; Direitos e deveres: Sara ZAGURY;

- Ser Homens ou Mulheres - métodos anticoncepcionais: Elizabeth AFONSO.

\section{I - INA UGURAÇÃO (29/03/2001)}

A aula inaugural foi presidida pelo Exmo. Sr. Dr. Juiz Siro DARLAN e reuniu cerca de 60 pessoas, incluindo o Sr. Subsecretário de Ação Social do Estado do Rio de Janeiro, vários técni- cos do Juizado, convidados e alunos de ambos os sexos. Foram apresentados os técnicos responsáveis por distintos setores do Juizado, com atribuições de: localização de crianças desaparecidas, adoção e tutela, abuso sexual, drogas, banco de empregos, serviço social e fiscalização de entidades de abrigo.

Inicialmente foi dada a palavra ao Sr. Subsecretário de Ação Social do Estado do Rio de Janeiro, que tratou dos projetos do governo na área social.

A seguir, falou o Dr. Siro DARLAN sobre o programa e seu objetivo principal de assegurar os direitos dos filhos menores através da ação junto aos pais. Todos os pais presentes já seriam, em princípio, passíveis de uma punição, sendo o curso uma oportunidade para corrigir as falhas, garantindo direitos e estabelecendo obrigações. Citou os valores, dignidade e respeito como norteadores das ações e falou da responsabilidade dos pais de terem o número de filhos que possam criar, donde a necessidade de planejamento familiar. O curso é constituído de 8 encontros e por eles já passaram cerca de 500 pais até hoje. Estes recebem vale transporte e bolsa de alimentos durante o curso.

Essa iniciativa deu origem à criação de uma cooperativa de trabalho criada pela Escola de Pais, e ao programa Família Solidária, constituída de famílias que, por um período limitado de 12 meses, apadrinham uma família necessitada com a contribuição de 1 salário mínimo.

Outros núcleos de Escola de Pais foram criados: 03 Postos através da Fundação para a Infância e Adolescência (FIA) e nos CIEPs de Vila Pinheiro e Penha. O esperado é que se multipliquem e que essa proposta se torne efetivamente uma política do governo estadual.

Estiveram presentes ao encontro, pela UIPES/ORLA-BR: Bernardete LOBATO, Nora z. Ribeiro CAMPOS, José Maria ARRUDA, Maria SilviaNACAO (SESC/DN), Nazareth Figueira da COSTA, Vera Lúcia G. Pereira LIMA.

A equipe da UIPES/ORLA/BR elaborou as seguintes questões para nortear a análise das atividades realizadas:

1. Quais os objetivos que você percebe na atividade?

2 Acompanharam os trabalhos, através da UIPES/ORLA-BR: Vera Lucia Góes Pereira LIMA, Coord., Doutora em Educação UFRJ, representante da Sub-Região Brasil junto à Oficina Regional Latino-Americana da União internacional de Promoção da Saúde e Educação para a Saúde; Ana Lucia de Lima ARAUJO, bacharel em Direito, MS/FUNASA/CORERI, Grupo Assessor UIPES/ ORLA-BR; Bernadete de Lourdes LOBATO, educadora em Saúde Pública, SESC/DN; Carlos SILVA, coordenador de Saúde Escolar da SMS/RJ, UIPES/ORLA-BR; Graciela PAGLIARO, médica homeopata, Núcleo de Saúde Comunitária, ONG HAPS/ RJ; José Maria ARRUDA, mestre em Administração UFRJ, Grupo Assessor UIPES/ORLA-BR; Maria de Nazaré Figueira da COSTA, inspetoria de Ensino da SME/RJ; Maria Silvia NACAO, odontóloga, SESC/DN; Nora Z. Ribeiro CAMPOS, mestre em Educação UFRJ, Grupo Assessor UIPES/ORLA-BR; Regina SALLES, assessoria de Comunicação, MS/ FIJNASA/CORERJ. 
2. O que você destacaria na atividade desenvolvida?

3. A atividade mobilizou o grupo?

4. Houve pessoas que não se integraram?

5. Há aspectos que poderiam ser aprofundados ou alterados? Quais? De que forma?

6. Como você avaliaria a coordenação do trabalho?

7. De que modo a UIPES/ORLA/BR poderia integrar-se ao trabalho? (sugestões)

\section{ANALISE}

1. Conforme foi colocado, o objetivo principal é zelar pelos direitos da criança e protegê-la através do trabalho com os pais.

Outros objetivos percebidos são:

- trabalhar a informação, a sensibilidade, o resgate da auto-estima, o apoio social, a reintegração social, a responsabilidade pelos filhos menores;

- promover a sensibilização dos pais e prepará-los para lidar com os filhos sem violência;

- apoiar os pais na busca e criação de oportunidades de geração de renda;

- desenvolver atitude mais receptiva entre os pais (um desarmar-se) como preparação para uma relação de ajuda mútua.

2. Destacam-se a seriedade e mobilização da equipe de profissionais envolvida (por ex.: a coordenadora sabia com clareza a história de cada um dos participantes graças às entrevistas feitas anteriormente). Foi percebido na visita aos diferentes setores/programas do Juizado: organização, vitalidade, trabalho (movimento e ordem em todos os setores), mobilização dos profissionais.

3. A atividade mobilizou o grupo de participantes, embora alguns ainda se mostrassem um pouco arredios. A metodologia do trabalho em grupo e a adoção de técnicas de sensibilização (distantes da experiência dos participantes) são produtivas. Também observa-se a preparação de infraestrutura e recursos para que os pais possam acompanhar a atividade (creche, encaminhamento à escola), vale transporte, alimentação, etc.

4. Houve quem não se integrasse à atividade. Como se tratava do $1^{\circ}$ encontro, era difícil avaliar seu significado. Uma das participantes se mostrou ressentida por ter sido chamada, dizendo que quem a denunciou deveria também estar presente, para que ela pudesse se defender. A coordenadora interveio com segurança, explicando que a intenção não era esclarecer denúncias e sim oferecer oportunidade de apoio e redirecionamento da vida de cada um.

5. Naquele primeiro momento, não foram percebidos aspectos que pudessem ser alterados ou aprofundados. No entanto, com base no programa apresentado, poder-se-ia sugerir outros temas na linha da promoção e educação em saúde.

6. A coordenação do trabalho foi considerada excelente: segura, carinhosa, respeitosa e firme. Na apresentação de todos os presentes (inauguração) foi notada a ordem das apresentações - autoridades/equipe/convidados/participantes e houve entre os observadores quem sentisse falta do "nós".

7. Em princípio, a equipe da UIPES/ ORLA-BR deseja observar, aprender, integrar-se, analisar. Uma futura contribuição prática nas áreas da saúde e de promoção da saúde poderia ser considerada ou sugerida por ambas as partes (disponibilização de informações de interesse dos participantes, articulação de recursos, ação educativa, encontro com os coordenadores sobre promoção da saúde, etc.). $\mathrm{O}$ acesso à informação sobre a procedência das pessoas e outros dados disponíveis, com vistas a possíveis contribuições nas áreas de educação, saúde, geração de renda, etc., seria pertinente.

\section{II - APRENDENDO COM A MÚSICA $(05 / 4 / 01)$}

Estava presente um grupo maior de participantes do que na $\mathrm{l}^{\mathrm{a}}$ reunião. Regina Z., técnica do Juizado e uma das coordenadoras do curso, iniciou o encontro falando sobre a característica dos presentes. Todos tinham filhos em situação de risco - algum tipo de risco. Nestas reuniões buscava-se a melhoria da relação de cada um com a vida - a luz interior que iluminasse a própria vida. Regina é uma pessoa habilidosa na comunicação com os participantes.

A palestrante do dia foi Regina SÁ, musicóloga e participante da escola de pais, graças à parceria do Juizado com a Sadia. Na 
sua apresentação explorou a potencialidade da música, mostrando que a música sugere diferentes estados de ânimo. Tanto pode estimular a parte animal das pessoas, como pode despertar a espiritualidade. Para ela, o ser humano busca constantemente a alegria, que pode ser canalizada através dos sentidos. De todos os nossos sentidos, a audição tem sido muito agredida pela poluição. Essa poluição, acentuada pela música em alto volume, tem prejudicado o nível de audição das pessoas. Devese evitar os sons demasiadamente altos. Outra afirmativa é que a "felicidade" é fabricada. Ela, na realidade, repousa mais no que somos do que no que temos. Além disso, o trabalho é um elemento que gera saúde e eleva nosso bem estar, ao passo que o ócio é um convite à depressão. Em seguida, fez exercícios com os participantes utilizando desenhos e frases, trabalhando a música (teclado, canto, disco), o afeto, o abraço, os ritmos em geral, a partir dos ritmos corporais (coração, respiração, andar, fala, etc.) chegando à música. Foram salientados sentimentos como o despojamento ou as alegrias simples e grandiosas que a natureza (que nada custa) pode proporcionar, a satisfação de trabalhar e de produzir ou plantar (versus o ócio) mesmo em pequenos espaços de terreno, de cuidar das plantinhas (quem planta alguma coisa? quem tem espaço para plantar?). Utilizou uma técnica seqüencial interessante: desenho simples, seguido de música de Mozart e novo desenho, demonstrando como o segundo trabalho, após a exposição à música, é mais expressivo. Chamou a atenção para o significado do que cada um quer expressar através da arte/desenho, lembrando o exemplo de O Pequeno Príncipe (desenho da jibóia que engoliu o elefante). Seguiu-se um número de música com as pessoas de pé cantando e batendo palmas e outro, cantado e acompanhadas pelos 5 participantes com gestos apropriados, seguido da retirada sucessiva de palavras mantendo-se o gestual. E ainda, de canto com movimento corporal e mãos dadas, com dança estimulada por uma das coordenadoras, dança de roda e palmas, tapotagem e massagem feita aos pares, e uma oração final, O Pai Nosso, com mãos dadas e palmas. Sua apresentação, num total de 90 minutos, esteve sempre voltada para a espiritualidade. Os abraços, os apertos de mãos, os cumprimentos efusivos entre os participantes quebraram barreiras. O clima do grupo foi influenciado por esses exercícios. (Presentes: Nora Z. R. C., José Maria A., Carlos Silva, Vera Lucia G. P. L., Nazareth F. C.).

\section{ANALISE}

1. Foram percebidos os seguintes objetivos: atingir um estado de relaxamento (desarmar-se) e estimular uma disposição descontraída de alegria e aproximação com o outro, aceitação/retribuição de carinho, resgate/construção de autoestima.

2. Dentre as atividades desenvolvidas destacam-se: a música e seu efeito, o abraço, o dar-se as mãos, soltar o corpo ao sabor da música; a habilidade das coordenadoras em motivar a participação dos mais resistentes, nem sempre com sucesso; e a demonstração do efeito da música sobre o relaxamento e a criatividade. Apesar da oferta limitada de lápis de cor, houve o estímulo ao compartilhar.

3. A atividade mobilizou o grupo de modo crescente.

4. Poucas pessoas deixaram de se integrar: duas ou três não se mostravam receptivas.

5. No caso de necessidade de aprofundamento de alguns aspectos, propõese: maiores oportunidades de expressão corporal, dança, música, oficinas de sensibilização, jogos interativos, talvez em duas ou três sessões de musicote-rapia. A atividade foi muito interessante e na realidade o tempo disponível não permitiu um desdobramento maior. Poder-se-ia sugerir uma discussão sobre o aproveitamento integral dos alimentos obtidos em feiras, supermercados, etc.

6. A coordenação de Regina de SÁ, assessorada por Regina ZANDONADI, foi excelente (competentes, afetuosas, sensíveis).

7. A equipe da UIPES/ORLA-BR poderia integrar-se ao trabalho, inicialmente, observando, inserindo-se no contexto, analisando, discutindo e estudando sugestões, e propondo um debate com a equipe da Escola de Pais sobre o conceito de saúde e sobre os princípios e estratégias da Promoção da Saúde (incluindo questões relacionadas ao empoderamento do grupo de participantes e ao meio ambiente), com o propósito de incorporá-los ao programa. 


\section{III - O QUE SABEMOS FAZER COM AS MÃOS \\ $(19 / 4 / 2001)$}

Após o café da manhã servido a todas as famílias presentes, os pais foram levados de ônibus ao Sambódromo para a atividade do dia. $\mathrm{O}$ desenvolvimento da aula incluiu uma primeira abordagem na qual alguns pais fizeram depoimentos acerca de suas dificuldades, alegrias, angústias, medos, prazeres, preocupações, desejos em relação aos filhos, e responsabilidades por serem pais ou mães. Com relação a uma filha de 18 anos, “desencaminhada” pelo namorado, afirmou um pai que "quem come a carne, leva os ossos" e mandou a filha para fora de casa.

A educadora lembrou que os objetivos principais se resumem a ver nossos filhos "bem crescidos, realizados e bons cidadãos”. O adolescente é difícil porque nesta idade quer ter sua individualidade, ser diferente dos pais, ser do jeito dele. Por isso, afronta, enfrenta, desafia, mas a violência nestas circunstâncias é sempre a pior solução.

As atividades incluíram a procura em revistas velhas de imagens que pudessem descrever as relações com os filhos: situações de alegria, tristeza, necessidades, sonhos que os pais tenham em relação a seus filhos. Foram utilizados materiais simples, tais como: revistas velhas, cartolina, cola branca, lápis cera e tesoura, sendo estimulada a troca de revistas e tesouras (estas últimas em número menor do que o dos participantes). Alguns pais foram incentivados a darem explicações acerca de seus painéis. S. colocou imagens representando a família, a união, a mesa farta, o lazer e a comunicação entre as pessoas, o lar, a música; F. escreveu embaixo de uma figura de mãe com um filhinho: "mamãe tem que ser heroína, apesar de suas fraquezas”. Outra participante colocou a imagem de uma casa e de uma rua movimentada representando o desejo de que seu filho saísse da rua e voltasse para casa. A maioria optou por imagens que representassem um lar bonito e bem decorado, família, saúde, educacão, lazer, alimentação, trabalho, e outros. Um pai expressou seu desejo de que a filha fosse jogadora de basquete e o filho, jogador de futebol. Na síntese da atividade, chamou-se a atenção para a importância do diálogo em todas as circunstâncias e nunca o uso da violêneia. Por fim, os participantes foram incentivados a deixar a sala arrumada, recolhendo todo o lixo caído no chão.

(Presente, como representante da UIPES/ ORLA-Brasil, Nora Z. Ribeiro Campos).

\section{ANÁLISE}

1) Os objetivos percebidos foram: expressar sentimentos, desejos, preocupações, medos, expectativas dos pais em relação aos filhos (e às vezes em relação a si mesmos).

2) $\mathrm{Na}$ atividade desenvolvida destaca-se a disponibilização de espaço/tempo para que os participantes falassem, inicialmente e sem pressa, sobre seus problemas. Houve também o estímulo a que fossem compartilhados os materiais entre os participantes e, principalmente, à execução dos trabalhos artísticos (vejam que lindo ficou... será que você pode explicá-lo para nós?).

3) A primeira parte da atividade mobilizou parcialmente o grupo. A segunda contou com a participação de todos os presentes.

4) Não foi observada a não integração de algum participante, até porque o trabalho era individual, embora compartilhado, e exigia participação.

5) Alguns aspectos poderiam ser alterados em que pesem os limites de tempo -, aspectos logísticos, e a possibilidade de se dispor de outros materiais, eventualmente oferecidos aos participantes (tecidos, barro, tintas, sucata, etc.), proporcionando assim oportunidades mais diver-sificadas que permitissem a descoberta de talentos para atividades manuais.

6) Em matéria de conteúdo, o trabalho foi muito bom, tendo sido estimulado o cuidado, visando uma exposição no encerramento da Escola de Pais.

7) AUIPES/ORLA-BR poderia participar, por exemplo, na linha do fazendo arte e aprendendo saúde ou, ainda, criando espaço para intervenções que levantassem questões de saúde e educação.

\section{IV - CONHECENDO NOSSOS FILHOS $(26 / 4 / 01)$}

A reunião começou com menos de 30 participantes. A coordenadora Regina A. aproveitou o tempo, antes da chegada da palestrante Vania PIRES, para fazer uma avaliação das reuniões anteriores. Vania é psicóloga do Juizado de Menores, tem experiência com adolescentes, famílias e adolescentes infratores. Começou perguntando a faixa etária dos filhos dos participantes, concluíndo que a maioria era de crianças e, alguns, adolescentes. 

cente?

Por que a atenção concebida ao adoles-

- O adolescente ainda está em fase de formação, em busca de uma identidade; seu desenvolvimento está se completando. Por isso, é mais sujeito a mudanças do que o adulto. Em resposta a um comentário sobre adolescentes infratores, lembrou que a lei é feita para todos e não para casos particulares.

Em seguida propôs um exercício de fechar os olhos e imaginar: o nascimento do filho (tentar visualizar que tipo de momento foi) / um ambiente tranquilo e lindo / a criança em seus braços naquele ambiente / o que você deseja para essa criança / o que você pode fazer por ela / se tem agido bem e se pode agir melhor. Para aqueles que têm filhos adolescentes, propôs visualizá-los diante de cada um / perceber que o amor continua igual e que o seu propósito é o de fazer o melhor por esse filho. Em seguida, pediu que os participantes se transportassem de volta para a sala, sentindo o corpo sentado na cadeira, e que abrissem os olhos.

Após o exercício, solicitou comentários:

- mãe com filha de 16 anos: consegui visualizar seu nascimento.

- mãe de uma filha de 19 anos - nasceu (a criança) em momento difícil, com 1,100 kg e 38 cm. (A mãe) rejeitava até o nascimento porque tinha outro filho de 1 ano. Mais tarde (a criança) fugiu de casa e hoje ela (a filha de 19 anos) tem 2 filhos. Visualizou o nascimento e tudo o que não deu à filha, e outra atitude dando-lhe carinho.

Devemos ser amigos de nossos filhos, disse a palestrante. Ao avaliar nossa relação com nossos filhos, devemos ser corajosos, vendo também nossos erros. Dar conforto não significa dar carinho. O carinho é também fundamental.

Prosseguindo, afirmou que precisamos estar atentos às fases pelas quais passam nossos filhos. Poder-se-ia reconhecer 8 fases no desenvolvimento infantil, sendo a primeira a de confiança básica, isto é, ter suas necessidades satisfeitas, não apenas de alimento, mas de carinho no pegar, acariciar, e na maneira de dar o alimento, pois isto faz com que a criança comece a desenvolver uma sensibilidade fundamental e a conquista de confiança. A última fase é a de integridade do ego (ou desesperança, no caso contrário). Quando as pessoas adquirem esse sentimento de esperança, tornam-se capazes de cuidar dos outros: o sentimento de esperança faz a gente ter força para viver; mesmo na dificuldade. Quando a criança começa a crescer, ela vai se defender, vai adquirindo autonomia. Muitas vezes a criança confunde carinho com sexualidade. Por isso, freqüentemente surgem casos de abuso com pessoas conhecidas da criança.

É obrigação dos pais cuidar da criança e colocá-la na escola na fase própria, onde ela trabalhará temas importantes como: sua cidadania, a questão moral, etc. Toda criança necessita conhecer seus limites e saber o verdadeiro sentido do sim e do não. Se ela apenas ouve “nãos”, não terá condições de saber o que isso realmente significa. Deve-se ter cuidado com o que se diz ao filho. Não dizer sempre coisas negativas, que ele possa internalizar; por exemplo: você é burro; você não presta para nada; você não devia ter nascido, etc...

Na adolescência, surgem mudanças típicas de comportamento: a oposição, o desafio, a transgressão, o exercitar-se e testar o pai e a mãe. Os pais precisam de bom senso. Nessa fase há a afirmação da orientação sexual. A sexualidade está sujeita a muitas influências, entre elas a da TV. É importante conversar muito com o filho, perguntar o que se pode fazer por ele e usar o bom senso. Não há receitas, porque cada caso é um caso.

\section{Relatos:}

- O filho sai da escola e fica na rua (9 anos). Chega à noite, e não sei (a mãe) o que fazer para mudar a situação. A criança diz que fica brincando. - Mora no morro e a mãe acha que quando se mudar para Cabuçu, as coisas podem melhorar.

- "Se a gente não adota o próprio filho, o mundo vai adotar", “cabeça vazia é arte do cão”. O filho esteve ou está no Padre Severino.

- A mãe R. tem 7 filhos, sem pai. Já viveu na rua com os filhos. O mais velho tem 13 anos. Atualmente foge e rouba o dinheiro da mãe para gastar no fliperama. R. se diz cansada do filho e sente vontade de largá-lo de mão.

Vania chamou atenção para a influência do temperamento, que nasce com a criança, e é diferente mesmo entre os filhos. O caráter é formado na relação com os pais e a personalidade integra o temperamento e o caráter. Foi colocada a questão do limite, “o que pode e o que não pode”, e o não na hora certa. É preciso que a negativa tenha explicações claras e que sejam descobertos outros interesses substitutivos.

Por último, um rapaz pediu a palavra e disse que gostaria de não participar mais porque só ouvia o problema dos outros, tendo sido rejeitado pelos demais que reagiram aplaudindo veementemente a coordenadora. Esta disse estar ali para aprender e ajudar, e se sentia feliz por isso. 
(Estiveram presentes Ana A., José Maria A., Nora Z. R. C., Vera Lucia G. P. L.).

\section{ANÁLISE}

1. Percebem-se objetivos de sensibilização e fortalecimento da relação pai/mãe e filho, assim como a discussão de informações sobre as necessidades da criança e do adolescente e a importância da colocação de limites.

2. Quanto à atividade desenvolvida, destaca-se o exercício feito com o grupo (visualização do nascimento de um filho, evocação dos sentimentos experimentados então e do primeiro contato físico entre mãe e filho, associação com um ambiente tranqüilo e prazeroso, transporte imaginário de filho e mãe para tal ambiente, concentração nas aspirações para aquele filho e visualização do que cada um fez ou poderia fazer para realizar suas aspirações).

3. A atividade mobilizou o grupo e se seguiu de alguns depoimentos. O encontro levou os presentes a pensar sobre suas responsabilidades como pais. Permitiu que trouxessem para o grupo suas angústias e problemas. Os encontros anteriores trabalharam o clima dos participantes e do grupo e serviram de introdução para que os participantes pensassem nas suas famílias.

4. Houve poucas pessoas que não se integraram. Quanto à pessoa que manifestou seu descontentamento em ter que ouvir os problemas dos outros, faltou sensibilidade para perceber o quanto se aprende com a experiência alheia. A psicóloga colocou-se muito bem falando de sua disponibilidade e prazer em trocar com todo o grupo a sua experiência e conhecimento.

5. Aspectos que poderiam ser aprofundados (em que pese a limitação de tempo) seriarn, por exemplo, explorar mais a questão do NÃO na relação pais e filhos, assim como a do SIM. Por que não e por que sim? E, ainda, a questão da coerência, levando as pessoas a repetirem um pouco sobre o que as motiva a dizer um não ou um sim para o filho (se é o seu estado emocional no momento, ou se é a ação da criança que está em jogo). A relação pais e filhos é um tema muito rico e importante e me- receria ser mais aprofundado, aproveitando-se as questões e dificuldades que surgem naturalmente no debate, assim como as necessidades da criança e do adolescente em função das fases de desenvolvimento. A responsável pela atividade fez o possível dentro do limite de tempo previsto. $\mathrm{O}$ modo sugerido de aprofundamento seria reservar-se uma carga horária maior para o tema ou mais uma ou duas sessões.

6. A coordenação do trabalho foi muito boa, alcançando a motivação e mobilização do grupo e sua participação na atividade.

7. Com relação a UIPES/ORLA-BR, procura-se acompanhar os trabalhos, aprender e observar criticamente. Na reunião em pauta, sentiu-se a possibilidade de aprofundar certos temas como a questão do sim e do não já abordada, que traz outras questões correlatas como a necessidade de brincar/exercitar-se (o significado do brincar), a aquisição de autonomia $\mathrm{X}$ responsabilidade e o papel do adulto. Seria interessante criar-se uma oportunidade para a troca de observações com a equipe de profissionais. Observa-se que há bastante espaço para a introdução de temas de saúde, ouvindo os participantes e estimulando-os a se expressarem. É conveniente definir recursos materiais e humanos, em áreas como: acompanhamento do crescimento, nutriçao/ aproveitamento dos alimentos, verminoses, vacinação, saúde oral, problemas dermatológicos. E outras, como: meio ambiente, recreação, prática de esportes, recursos culturais, etc.

\section{V - ÁLCOOL E DROGAS (03/5/2001)}

Houve pequena preleção inicial, enquanto se aguardava a chegada da palestrante convidada, que não compareceu. A sessão foi então realizada sob a orientação das coordenadoras do curso e a participação de Graciela PAGLIARO, médica, homeopata, que compareceu pela $1^{\mathrm{a}}$ vez a convite da UIPES/ORLA-BR. Contou com 29 participantes. Anunciou-se a presença de alunos de Comunicação da Universidade da Cidade para produzirem um vídeo de 10 minutos.

Graciela apresentou-se como membro da ONG Homeopatia Ação pelo Semelhante, que 
realiza um projeto de educação em saúde e atendimento no Morro dos Cabritos. Deu uma explicação inicial sobre a homeopatia, afirmando que não se trata de uso de chás ou infusões. É diferente da fitoterapia, acrescentou. O tratamento com homeopatia é feito através do uso da energia de substâncias da natureza (dos reinos animal, vegetal e mineral), extraída através de diluição e sucussão (agitação). Há uma técnica própria de preparação e as doses dos medicamentos são mínimas e repetidas. A homeopatia valoriza muito a relação médico/paciente, sendo as consultas sempre longas. O paciente é estimulado a se expressar e é visto como uma pessoa integral. Segundo Regina Z., o floral baseia-se em pressupostos semelhantes e é específico das flores, reconhecidas como partes especiais das plantas, responsáveis por sua germinação e reprodução, portanto, ricas em energia.

Regina Z. relatou, como ilustração, sua experiência num parque ecológico, no qual "pediu licença à natureza” e entrou; fechou os olhos e pediu que algumas flores se apresentassem; colheu-as e as colocou numa vasilha branca e transparente com água. O vaso foi exposto ao sol por 2 horas, tempo em que as flores ressecam (desidratam) e a “energia” passa para a água. A água tintura mãe - contém a energia das substâncias imersas e é terapêutica.

- Quando o neném nasce, a gente coloca a água (do banho) ao sol para aquecer - disse uma das presentes. Várias pessoas faziam o mesmo.

Cada flor tem suas características (forma, cor, perfume). Considera-se que as características de cada flor podem combinar com as características de uma pessoa ou de um estado físico ou emocional. Foi citado o exemplo do cactus com raízes longas e muita água dentro do caule, assim como espinhos para sua defesa. As pessoas também podem ter seus espinhos. Se várias pessoas possuem “espinhos”, elas se rejeitam - disse Regina. Na homeopatia buscam-se as semelhanças entre as pessoas e os sintomas desencadeados através da experimentação homeopática. Substâncias que desencadeiam problemas de saúde, são usadas em doses mínimas como terapêutica daqueles males.

Passou-se à discussão sobre drogas. Uma forma de definí-las é considerá-las como substâncias que causam dependência física ou psíquica (vício), tolerância (o organismo exige doses crescentes para atingir o mesmo efeito), além de produzirem alteração da consciência, do comportamento, do humor e da vida de relação. Nesse caso, há aquelas que têm efeito depressor (produzem calma, sonolência, torpor) e aquelas que têm efeito excitante (produzem euforia, agitação). Falou-se em síndrome de abstinência (alterações físicas e mentais que surgem com a retirada da droga) e em overdose (ingestão de drogas em excesso culminando com a falência do organismo).

Outro conceito de droga diz respeito a qualquer substância introduzida no organismo (excluindo-se os alimentos) que possa ter finalidade terapêutica e provocar efeitos não desejáveis (colaterais), e até graves, quando tomada de forma imprópria ou em excesso.

Foi perguntado se a homeopatia poderia causar dependência. Graciela respondeu que não, esclarecendo que só nos casos em que as pessoas têm mania de tomar remédio.

Nas palavras de uma das presentes, ex usuária de drogas segundo disse, a cola produz alucinação, a maconha, uma onda de riso e depois fome e "lombeira “, e a cocaína é a pior delas, provocando reações de susto e sensação de perseguição. Quanto mais se cheira mais se quer, para aliviar a sensação desagradável. pantes foi:

Outra questão apresentada pelos partici-

- Existe alguma droga que não seja prejudicial à saúde? Regina Z. falou nas diferenças entre as pessoas de se tornarem viciadas ou não em, por exemplo, álcool. Regina A. citou o exemplo da cerveja tomada em quantidade moderada (1-2 copos) no final da semana ou em dias especiais, porém sempre mantendo o auto-controle e sabendo parar.

- Meu pai tomava cerveja preta no almoço, com o tempo passou a cerveja comum, depois cachaça e no final álcool puro. Aí já tremia quando não bebia e no final não falava coisa com coisa.

- O que me revoltou mais, quando eu era adolescente, foi meu pai achar que eu fazia o que eu não fazia. Queria examinar meu nariz. Quando eu fiz, ele não notou, porque eu baixava a cabeça e não encarava...

- Meu pai bebia muito e perdia tudo. Batia na minha mãe. Fugi de casa e fui para a Cinelândia onde me juntava com outras crianças de rua. Pedia e roubava. As crianças se juntavam, roubavam coisas, subiam o morro para vender, compravam cola e faziam "prica de cola". Fui pegando o vicio e na rua fui pegando experiência. Comecei a assaltar e a ameaçar até com caco de garrafa para comprar mais cola. Usei cocaína. No Andarai, havia o "Cheiródromo", único lugar onde se podia cheirar. Com a cocaína cheguei à prostituição com 10 anos. Havia homens velhos que gostam de abusar: promessas, banhos, câmeras escondidas, filmes de vídeo, vendas para fora. O pior era a cocaína; a pessoa se torna capaz de tudo. Tinha uma amiga grávida que teve uma criança que nasceu dependente e 
fez tratamento. Com 14 anos fui presa e levada para a FUNABEM, na Ilha do Governador. Aprendi a fazer artesanato, a cozinhar. As pessoas produziam e ganhavam um dinheirinho. $\mathrm{Na}$ instituição tem muita coisa ruim, mas se pode chegar ao que é bom. Fiquei 2 anos e não queria sair da instituição. Depois procurei a Igreja Evangélica e me recuperei. (Hoje tem 29 anos e 5 filhos; acabou o relato aos prantos, sendo abraçada e consolada pelos presentes).

Dr. Siro DARLAN, também presente, revelou que $70 \%$ da violência com as crianças é praticada pelos próprios pais, que por sua vez sofreram violência quando pequenos. Tal dado contradiz a conviç̧ão de que as crianças devam ser mantidas com a família para serem protegidas. É preciso, pois, estar atento no sentido de evitar a reprodução desse comportamento abusivo. Perguntado sobre o que fazer quanto ao vício, disse que a pessoa, para amar os outros, precisa amarse a si mesma e o usuário de drogas não se ama pois tem um comportamento auto-destrutivo. Precisa de ajuda, porque na realidade é uma pessoa doente. Não é caso de punição, mas de tratamento e de aprender a crescer, cada um, com a experiência do outro.

(Compareceram: Ana A., José Maria A., Graciela P., Nora Z. R. C. e Vera Lucia G. P. L.).

No dia seguinte (04/5), foi a comemoração de Páscoa das crianças que estão em abrigos. Os participantes da Escola de Pais foram convidados a comparecer.

\section{ANÁLISE}

1. Em primeiro lugar, houve a preocupação de dar seguimento aos encontros na ausência da palestrante convidada, na mesma linha observada anteriormente, e de criar um clima de aproximação entre os presentes. Aproveitou-se a presença de Graciela para prestar esclarecimentos sobre homeopatia e outras terapias. Houve também a preocupação de abordar e esclarecer questões relativas ao tema da reunião - álcool e drogas - o que propiciou depoimentos importantes para trabalhar o assunto.

2. É importante destacar a participação dos presentes, estimulada pelas coordenadoras, que proporcionou, entre outros, um depoimento de vida relatado por uma participante, com muita emoção, a partir de uma infância sofrida, experiência de vida na rua, uso de dro- gas, prostituição ainda na infância, prática de delitos, recolhimento à FUNABEM. O depoimento foi relevante para todos e propiciou algumas questões para melhor compreender a origem do problema e suas conseqüências.

3. A atividade mobilizou o grupo e estimulou o relato de experiências com o uso de drogas e dúvidas adequadamente respondidas pelas coordenadoras.

4. A maioria das pessoas se integrou na atividade. No entanto, observou-se a ausência de um participante que no encontro anterior queixara-se de desinteresse em assistir às reuniões, alegando não saber porque estava ali ouvindo os problemas dos outros.

5. O assunto se presta a muitos aprofundamentos: discutir com os presentes a importância do diálogo entre pais e filhos; tratar com maior clareza os sinais que podem denotar o uso de drogas (mudança súbita de comportamento, queda no rendimento escolar, dificuldade de concentração, etc.) e salientar cuidados que os pais podem ter, visando a prevenção do problema. Com relação às diferenças entre as pessoas para se tornarem viciadas, faltou fazer uma distinção entre tais efeitos para diferentes tipos de drogas e, também, quanto ao risco que existe para todos quando usam repetidamente certas drogas, enfatizando-se que uns podem se viciar mais facilmente e que o risco se relaciona também com outros fatores (personalidade, problemas econômicos e afetivos, influência do grupo de idade, etc.). Teria sido importante estabelecer uma correlação clara entre as situações de vida vividas pelos pais e sua relação atual com os filhos. A metodologia empregada tem sido a mesma, isto é, estimular as pessoas a se expressarem e se colocarem quanto aos depoimentos, numa troca contínua de experiências.

6. A coordenação dos trabalhos (Regina Z. e Regina A.) foi eficiente, conseguindo aglutinar o grupo e estimular a participação com habilidade.

7. A UIPES/ORLA-BR poderia participar ampliando a discussão (educação em saúde), reunindo e disponibilizando informações sobre os recursos disponíveis para trabalhar esse tipo de problema (a quem procurar, onde buscar ajuda). 


\section{VI - DIREITOS E DEVERES $(10 / 5 / 2001)$}

Coordenado pela Conselheira Sara ZAGURY, o objetivo do encontro era repensar e reaprender os direitos e deveres das crianças, pais, família, Município, Estado.

Projetou-se um filme de vídeo para ser cuidadosamente observado, visando a identificação de situações corretas ou erradas: menino na rua chamando menina em casa/menino chegando atrasado na escola/menina (Bianca) faltando à escola/comentário da professora sobre atrasos e falta/ Bianca tomando conta de bebê em casa/calor e os alunos indo para o exterior da escola por sugestão da professora/2 meninas levando bilhete e pirulito para Bianca/professora chamando a atenção de menino que dorme na sala e dos meninos atrasados, não deixando a menina se explicar/ menino que dormia na sala atendendo a uma freguesa no armazém do pai, deixando cair um ovo que se quebra e olhando temeroso para o pai/professora chamando os pais de Bianca/Bianca cuidando do irmãozinho e não indo à escola para $\mathrm{a}$ mãe trabalhar/Bianca indo à escola com os dois amigos e levando um presente para a professora/ e finalmente uma referência ao Estatuto da Criança e do Adolescente (ECA).

Após a apresentação do vídeo, a sala foi rearrumada num grande círculo com todos os participantes para tratar dos deveres do pai, mãe e avó para com os filhos e netos. Perguntou-se: quais os deveres dos pais para com os filhos? As falas foram as seguintes: dar boa educação/saber ensinar o que é certo e o que é errado/respeito/não quero falar (mais tarde diria que quer saber é do direito da mãe)/criação, educação, alimentação/ pôr seu filho na escola/dar carinho e estar junto/ buscar o direito dele e lutar para que ele tenha atendimento/dever do pai é um e da mãe é outro - do pai, deixar o dinheiro, brincar com o filho quando pode, pai companheiro, e da mãe é cuidar das rotinas/discorda do direito do pai (separado) ver o filho/ver o pai e a mãe juntos sem briga/as crianças estão cuidadas (pelo pai?) e a mãe está na rua/receber assistência dos pais/ser entendida pela família e os pais entenderem o filho/dar educação religiosa ou não/o pai não deve tirar autoridade da mãe/quando se tem filho, a vida muda, tem que ter responsabilidade/respeito na escola/a criança se espelha nos pais/dar carinho, educação, saúde/amar e respeitar: a gente respeita para ser respeitado e aos próximos também/a criança tem que ter limite/sou pai e mãe de filhos de 14 e 16 anos, procuro acompanhar e orientar/estar atento/direito à profissionalização, vacinação, saúde, lazer/a importân- cia do exemplo dos pais/direito a ficar com os filhos, o filho mais velho é osso duro de roer, merecia ser filho da avó e não de mim e eu não merecia ter a mãe que tive: meu filho não merece que eu esteja aqui porque ele é "carne de pescoço" e Deus é um carrasco. Eu estou aqui pelos meus outros 4 filhos, não pelo mais velho que já acabou para mim.

Todos nós temos coisas legais e não legais, disse a conselheira. A arte de viver é desenvolver em nós o que temos de bom, pois temos consciência que o lado sombra nos prejudica. Existe o direito legal de que toda criança tenha escola com professora (caso não tenha, ir ao Conselho Tutelar e comunicar por escrito). Foi colocada outra questão: - quais as coisas graves que a gente não pode fazer com os filhos ? Outros relatos: a criança chega atrasada na escola e não pode entrar, fica no portão com tempo vago, vai fazer bobagem, vai para Copacabana, etc./tem 2 filhas de 2 pais; um dos pais casou outra vez e tirou a filha; a mãe não tem permissão de ver a filha na escola (o caso vai merecer um atendimento mais completo de toda a família; a mãe foi denunciada pela irmã por maus tratos a uma das filhas)/riscos na escola que a direçàio não vê Brincadeiras perigosas, cachorro perigoso, brigas e adultos atiçando a briga)/muitas escolas não tem guarda municipal.

Os participantes foram orientados a procurar a Direção da escola e, sucessivarnente, o CRE, o Conselho Tutelar, a Defensoria Pública para fazerem valer os seus direitos. Foi colocado que ninguém é obrigado a pagar carteirinha da escola, Caixa Escolar, creche, etc. Regina A. ficou de dar os endereços dos Conselhos Tutelares. O Conselho Tutelar pode chamar o pai para conversar e a Vara de Família pode tomar outras providências. É obrigação do Município, a gratuidade da escola e creche. A conselheira voltou à pergunta inicial, afirmando que coisas graves que não podem de modo algum ser toleradas são: espancamento, abuso sexual, violência psicológica. Outras recomendações por parte das mães surgiram: não deixar sentar no colo, estar de olho, quem mais abusa são os pais, padrastos, tios, avô, vizinho.

Os pais devem estar atentos e denunciar. Ao falar de espancamento, a conselheira disse que não se trata de um tapa ou palmada, "uma pancada não mata”. A reunião se encerrou com a história de uma das presentes que achava que o filho não prestava, não tinha mais jeito; ela ia para a igreja, até que um dia resolveu dizer para o filho que o amava muito e percebeu que o filho mudou.

(Presentes: Ana A., Graciela P., José Maria A., Regina S., Nora Z. R. C., Vera Lucia G. P. L.). 


\section{ANÁLISE}

1. Os objetivos percebidos incluíram: repensar e reaprender direitos e deveres das crianças, pais, família e Município; estimular a participação e expressão de sentimentos, percepções, etc.

2; A atividade desenvolvida voltou-se para a informação não só sobre direitos dos filhos e deveres dos pais, como de recursos e instâncias legais para fazer valer esses mesmos direitos.

3. Como aconteceu de outras vezes, a atividade mobilizou o grupo. As pessoas participaram e fizeram muitas colocações, trazendo à tona as principais necessidades e direitos dos filhos, estimulados e sublinhados pela coordenadora.

4. Uma pequena proporção de pessoas não se expressou oralmente, porém parecia acompanhar com atenção as falas da reunião.

5. Embora riquíssimo de exemplos, o filme projetado não foi discutido como parecia ser a intenção. Sua discussão por todos deveria ter antecedido os depoimentos dos presentes. Atendendo à insatisfação de uma participante, o direito dos pais poderia ter sido discutido.

6. A coordenação dos trabalhos foi boa quanto à mobilização do grupo e a preocupação em sublinhar as afirmações que tratavam dos direitos e deveres, embora sem explorar devidamente o video. Foi regular quanto à permissão para que casos particulares se alongassem, fugindo da questão em discussão; sabendo, no entanto, lidar com habilidade com manifestações de hostilidade entre participantes.

7 Num primeiro momento, é importante inteirar-se com maior segurança sobre os recursos e instâncias legais mencionados. Uma participação da UIPES/ORLA-BR, na linha da promoção da saúde e do empoderamento da população (desenvolvimento de poder das pessoas para a transformação social), passa necessariamente por uma visão precisa de direitos e deveres do ponto de vista legal, jurídico e politico-social. A possibilidade de integração ao programa de trabalho exige uma discussão mais ampla que envolva a equipe do Juizado e a UIPES/ORLA-BR.

\section{VII - SER HOMENS OU MULHERES} $(17 / 05 / 2001)$

Cristiane, egressa da $1^{\text {a }}$ Escola de Pais e Presidente da sua Cooperativa, foi a apresentadora do tema, com o apoio de Regina A. e Regina Z. Projetou-se um vídeo, com situações da vida cotidiana de um casal, Lucineide e Adelson, retratando uma realidade (tipo de moradia, nível social) compatível com a dos participantes. Lucineide fala das constantes reclamações do marido que não reconhece seu trabalho e não a ouve. Uma vizinha mostra uma mancha de baton na camisa de Adelson que foi lavar. São as seguintes as falas pensadas ou explicitadas: os homens não são para uma mulher só; filha, você tem que perdoar (lembrando-se do que a mãe dizia); não podia falar com ninguém (lembrandose de doenças venéreas contraídas através do marido no passado); homem que é homem não pega (Adelson falando com Lucineide sobre AIDS); isso, homem não pega de mulher (Adelson falando de AIDS com a mulher). Lucineide lembra-se que ouviu coisa diferente na TV. Preocupa-se e pensa: os casais bem casados são filhos de Deus mas, e a mancha de batom? Aparecem outras cenas com Adelson conversando com um amigo que procura alertá-lo sobre a importância da camisinha. Adelson se mostra cético e impaciente. Conta que esteve com uma mulher na rua. $\mathrm{O}$ amigo pergunta: usou camisinha? Na Rádio do Amor: o casamento protege da AIDS? Resposta: o que protege mesmo é a camisinha. Lucineide acha que se o marido usar camisinha é uma confissão de culpa? mas qual a garantia se ele não usa? Ela se preocupa com os filhos adolescentes (uma moça e um rapaz “destrambelhado" e "farsista”). Ela quer alertar os dois, mas se surpreende quando a filha lhe diz que já tinha relações com o namorado e se protegia: ambos são bem informados e usam camisinha.

O filme é muito bem feito, os diálogos e as situações são realistas e repetem tabus e preconceitos. Cristiane e as coordenadoras estimularam a discussão e esclareceram que hoje as mulheres casadas são as maiores vítimas, e que pessoas casadas não estão livres de serem contaminadas: “quem nunca usou deve experimentar”. Cristiane fez uma demonstração de como colocar e retirar a camisinha com segurança. Mostrou também a “camisinha” feminina.

Em seguida, os participantes foram estimulados a falar sobre o que é ser homem ou ser mulher. As falas foram as seguintes: o homem é mais safado (trai a mulher), é machista (termo definido como ser autoritário, metido a forte, mandão, que tem poder), tem vergonha de conversar sobre 
essas coisas (por que? por medo, para a mulher não ser infiel, o homem pode falar tudo). Quanto à mulher: é fiel o que foi contestado (depende).

Cristiane e as coordenadoras responderam a perguntas e falaram sobre as formas de contaminação: aleitamento, quando a mulher é portadora do vírus (deve-se recorrer ao banco de leite e não a outra mãe, o que hoje em dia é proibido), pico na veia (a defesa seria através de seringa descartável, de uso pessoal), sexo oral, anal, vaginal. Os participantes foram orientados a procurar os postos de saúde: todo posto ensina como usar os métodos contraceptivos e dispõe de camisinhas. Doença venérea não se pega em banheiro (pode-se, sim, pegar doenças de pele). Com relação aos exames realizados nos postos de saúde, todas as pessoas têm o direito a ter acesso aos resultados e a repetir o exame para confirmá-los. Esclareceu-se ainda que os vírus sofrem mutações, donde a dificuldade em produzir vacinas; no entanto, a AIDS não é mais uma sentença de morte, caso haja acompanhamento e tratamento, embora ainda não haja cura. O soro positivo pode não apresentar a doença, porém contamina. Para terminar, falou-se dos papéis do homem e da mulher na sociedade atual, na qual é cada vez mais comum a mulher sair para trabalhar e o homem participar das tarefas da casa, disso podendo resultar desencontros e insatisfação. Enfatizou-se a necessidade do encontro e de se buscar formas de contornar este problema com compreensão, para que os dois se complementem. Encerrou-se com a apresentação, pela Cristiane, de sua história de vida: além de egressa da $\mathrm{l}^{\mathrm{a}}$ Escola de Pais, fez capacitação para Auxiliar. de Enfermagem, dirige a Cooperativa da Escola de Pais, tem um novo projeto de vida para o futuro e representa um exemplo vivo da importância do espírito de luta para a superação dos problemas pessoais. G.P.L.).

(Presentes: Ana A., Regina S., Vera Lucia

\section{ANALISE}

1. Discutir questões de gênero e a prevenção de doenças sexualmente transmissíveis, em especial a AIDS, foram os principais objetivos deste encontro.

2. A atividade foi muito bem conduzida, destacando-se o exemplo de vida de Cristiane e a adequação do filme apresentado.

3. O grupo se manteve todo o tempo mobilizado e participativo.

4. Sempre há uns poucos que não se expressam, porém se mantêm numa atitude atenta.
5. As questões que não foram abobadas e são, no nosso entendimento, de fundamental importância, foram a paternidade responsável e o planejamento familiar. Certamente, haveria necessidade de um tempo inteiro dedicado a esse tema.

6. A coordenação do trabalho foi muitíssimo eficiente, incluindo-se nessa avaliação a atuação da apresentadora, abordando o assunto com segurança, clareza e objetividade.

7. Toda essa questão é de grande interesse para a equipe da UIPES/ORLA-BR, que tem como mobilizar profissionais experientes, tanto no trato desse tipo de conteúdo como na utilização de recursos metodológicos participativos.

\section{VIII - SOLENIDADE DE FORMATURA}

Já tínhamos dado por encerradas as nossas anotações, mesmo porque desejávamos compartilhá-las com os responsáveis pelo projeto no dia da formatura, quando decidimos acrescentar outras observações ao presenciarmos a solenidade que encerrava a $8^{\text {a }}$ Escola de Pais. Percebemos que a formalidade, o caráter solene do acontecimento, as autoridades presentes, a indumentária do grupo de participantes (incluindo alunos de turmas anteriores), as falas e orações oficiais e o cerimonial, sempre dirigidos aos formandos, tinham um sentido especial e integravam a proposta sócio-educativa desenvolvida. Tudo ali era significativo - sobretudo a atmosfera afetuosa, respeitosa, incentivadora e responsável para com a população beneficiária. A essa homenagem, os formandos respondiam com atitude também respeitosa e atenta, às vezes efusiva ao aplaudirem a paraninfa e os colegas que recebiam os diplomas, e emocionada ao ganharem flores dos respectivos filhos. Até os mais contestadores aparentavam viver um momento de alegria e esperança.

A solenidade de formatura da $8^{\mathrm{a}}$ turma de Escola de Pais, realizada pela $1^{\text {a }}$ Vara da Infância e Juventude, ocorreu em 24/5/2001, no Auditório da Associação dos Magistrados do Rio de Janeiro (AMAERJ), no Tribunal de Justiça, à Av. Erasmo Braga, 115, $4^{\circ}$ andar - Bloco J, Centro. Presidiu-a o Sr. Dr. Juiz Siro DARLAN de Oliveira; compondo, também, a Mesa, os representantes da Secretaria de Ação Social do Governo do Estado e da Secretaria de Desenvolvimento Social da Prefeitura do Rio de Janeiro, a Presidente da FLVRJ Maria Lucia KAMACHE, Francisco Waldemir RÊGO, proprietário dos restaurantes La Mole, e 
Regina SA, paraninfa da turma, que ali também representava a SADIA.

Iniciou-se a solenidade com o Hino Nacional, cantado pelos presentes. A seguir, Regina ZANDONADI, uma das coordenadoras do curso e mestre de cerimónia do evento, referiu-se aos principais dados biográficos do antropólogo e homem público Prof. Dr. Darcy Ribeiro, cujo nome foi dado à turma que se formava. O Dr. Juiz Siro DARLAN tomou então a palavra e lembrou que o programa da Escola de Pais vai ao encontro do Estatuto da Criança e do Adolescente (ECA), que em seu Art. 129 afirma: uma das medidas aplicáveis aos pais em conflito com os filhos é a realização de um curso de orientação e apoio. Falou na doutrina da proteção integral à criança, que graças ao ECA muda, a partir de 1990, a maneira de lidar com a criança, responsabilizando os pais e toda a sociedade. É importante que, além do texto legal, as pessoas adquiram essa consciência e uma nova atitude para que direitos e deveres sejam efetivamente respeitados. Isto é cidadania. Lembrou outras conquistas legais no Brasil, como o direito do negro, o da mulher e, há uma década, o direito da criança. O único caminho para reduzir a violência é tratar com respeito e dignidade os filhos de vocês, afirmou, dirigindo-se aos formandos. Reafirmou que todos são capazes de trabalhar e assumir suas responsabilidades, porém o Juizado oferece apoio pelo período de 1 ano, através do programa Família Solidária que direciona um auxilio de 1 salário mínimo mensal, por família, para ajudá-los a se integrarem à vida social com trabalho e alguma geração de renda. Em troca, exige-se o cumprimento dos deveres para com os filhos, como por exemplo mantê-los na escola, e a freqüência mensal às reuniões promovidas pela equipe da Escola de Pais, para acompanhamento. Citou, ainda, a Cooperativa da Escola de Pais, em funcionamento, que abre oportunidades de trabalho, assim como as cadeiras de engraxate no prédio do Tribunal de Justiça, no centro da cidade. São iniciativas dentro de uma proposta mais ampla de criação de pólos de trabalho. O objetivo maior é que os Núcleos de Escolas de Pais se multipliquem por toda a cidade. Com essa preocupação, a la Vara da Infância e Juventude do Rio de Janeiro tem procurado aprimorar esse modelo, disponível para outros setores do poder público.

Todas as autoridades presentes se manifestaram, reafirmando a importância da iniciativa. A representante da Secretaria de Desenvolvimento Social da Prefeitura referiu-se ao interesse em apoiar a abertura de postos de trabalho para favorecer a integração social das famílias. Há, no momento, 5 Núcleos de Escola de Pais no Rio de Janeiro, e a comunidade de São Gonçalo reivindica a organização de mais um, além de uma padaria, visando a profissionalização. Foi também informado que o governo do Estado destinou 10 casas de conjuntos residenciais a 10 famílias necessitadas da Escola de Pais, e pretende-se que este número venha a ser ampliado.

Após as falas da paraninfa e da oradora escolhidas pela turma, foram introduzidas no auditório os filhos e filhas dos formandos, trazendo flores para os pais. Foi lido por um dos formandos, e repetido pelo grupo, o texto do juramento, que se reportava aos deveres e compromissos dos pais. Seguiu-se a apresentação de um coral, organizado por Regina Sá, com alunos de turmas anteriores. A cerimônia encerrou-se com a distribuição de diplomas, acompanhando a chamada individual, e homenagens às autoridades presentes. Ao final, os participantes, equipe e autoridades foram convidados pelo Sr. Francisco Waldemir Rêgo, proprietário do restaurante La Mole, na Barra da Tijuca, para comemorar o evento.

\section{IX - AVALIAÇÃO REALIZADA COM OS PARTICIPANTES $(31 / 5 / 2001)$}

Na semana seguinte, foi realizada uma avaliação com os participantes. O objetivo era ouvilos sobre o que sentem, pensam e opinam quanto ao conjunto das atividades desenvolvidas no período, contribuindo assim para o desenvolvimento de programas futuros. Inicialmente, projetouse o vídeo produzido pelos alunos da Escola de Comunicação da Universidade, registrando os encontros. Os presentes se divertiram e apreciaram o trabalho realizado, reproduzindo momentos significativos das reuniões. Posteriormente, foi divulgado o crescimento deste tipo de trabalho na cidade do Rio de Janeiro, mostrando o empenho em que o mesmo se desenvolva e a efetividade de seus resultados. A seguir, foram colocadas duas perguntas cujas respostas estão organizadas segundo "a metodologia do Discurso do Sujeito Coletivo, de Fernando EEFÈVRE ${ }^{3}$. De acordo com este método, as falas individuais possibilitam o resgate do imaginário social.

1 LEFÈVRE, E; LEFÈVRE, A. M. C.; TEIXEIRA, J. J. V. (Orgs.). O discurso do sujeito coletivo. Uma nova abordagem metodológica em pesquisa qualitativa. Caxias do Sul: EDUCS, 2000. 
$1^{\text {a }}$ pergunta: Qual o seu desejo ao chegar aqui? Como você chegou aqui? (Esta pergunta traduz o desejo de conhecer a expectativa das pessoas com relação ao projeto).

\begin{tabular}{|ll|}
\hline \multicolumn{1}{|c|}{ Idéias Centrais } & \multicolumn{1}{c|}{ Discurso do sujeito coletivo - DSC } \\
\hline Desespero & $\begin{array}{l}\text { "desesperada, vontade de jogar tudo para o alto. Disposta a dar meus filhos e } \\
\text { sumir" }\end{array}$ \\
\hline $\begin{array}{l}\text { Sensação de estar perdida } \\
\text { Desconfiança }\end{array}$ & $\begin{array}{l}\text { "só chorava, chorava, igual a perua doida" } \\
\text { "achando tudo uma babaquice, palhaçada, que não me dariam o que queria" } \\
\text { "na hora que entrei, não gostei" }\end{array}$ \\
\hline Incômodo & "me senti incomodada de estar aqui" \\
\hline Onipotência & "pensei que sabia tudo com os filhos e vi que não sabia nada" \\
\hline Stress como uma boa causa & "fui chamado por causa dos filhos e me senti bem" \\
\hline Dúvidas/ Medos & "chateada, fui gostando aos poucos" \\
\hline Aprendizagem & $\begin{array}{l}\text { "com muitas dúvidas" } \\
\text { "entrei com medo, insegura, com o que vai acontecer com meu filho" }\end{array}$ \\
& $\begin{array}{l}\text { "aprendi muitas coisas com relação aos meus filhos" } \\
\text { "aprendi a falar melhor com meus filhos, chamava de FDP e agora sei que } \\
\text { não é filho de nada disso" } \\
\text { "muita coisa aprendi aqui. Aprendi a lidar com o marido e ensinar o marido } \\
\text { a ser bom pai." }\end{array}$ \\
\hline Formatura e seu símbolo & "depois que vi a formatura é que gostei" \\
\hline
\end{tabular}

\section{$2^{\mathrm{a}}$ pergunta: Quais os temas das reuniões de que vocês se lembram?}

\begin{tabular}{|c|c|}
\hline Idéias centrais & Discurso do sujeito coletivo - DSC \\
\hline Sexualidade, drogas, AIDS & $\begin{array}{l}\text { "AIDS e o depoimento da mãe" (da outra turma) } \\
\text { "drogas e sexualidade" }\end{array}$ \\
\hline $\begin{array}{l}\text { Responsabilidade da paternidade } \\
\text { e da maternidade }\end{array}$ & $\begin{array}{l}\text { "como devemos tratar nossos filhos; ser homem; ser mulher; ser mãe; } \\
\text { ser pai" "tudo é culpa da mãe, e o pai ?" }\end{array}$ \\
\hline Questão duvidosa & $\begin{array}{l}\text { "aula com a Dra. Zara, eu gostei" } \\
\text { "aula com a Dra. Zara, eu não gostei" }\end{array}$ \\
\hline "Aulas" como forma de terapia & $\begin{array}{l}\text { "o trabalho com artes plásticas, coloquei o que não consegui a falar" } \\
\text { "na música fiz viagem" } \\
\text { "aula de música, uma terapia" } \\
\text { "brincando de roda, bater palma, é uma Terapia" } \\
\text { "aula de arte, colagem" }\end{array}$ \\
\hline Terapias alternativas & $\begin{array}{l}\text { "homeopatia, muito melhor que alopatia" } \\
\text { "dos florais" }\end{array}$ \\
\hline Propostas & $\begin{array}{l}\text { "dança" } \\
\text { "música (a música dissolve, alivia, se ouvirmos música violenta, somos } \\
\text { agressivos; se música razoável, somos mais calmos)" } \\
\text { "outras culturas no Brasil (nossa cultura é nossos filhos)" } \\
\text { "dividir em grupos menores para que todos possam participar (em } \\
\text { grupos menores a gente nunca se separava)" }\end{array}$ \\
\hline Pedido de colaboração & $\begin{array}{l}\text { "gostaria de solicitar que mais empresas colaborem com o projeto, não } \\
\text { só materialmente, mas através de pessoas que ajudem, como fez a } \\
\text { SADIA" }\end{array}$ \\
\hline
\end{tabular}

Neste momento J. e R. se confrontam, pela segunda vez, e são retiradas da sala.

Durante a rodada seguinte de respostas, uma das mães perguntou se a coordenação as considerava culpadas pelo que acontece com os filhos. Com muita propriedade, Regina Z. se diz mãe, com todas as dificuldades de qualquer mãe, e que seria injusta se julgasse alguém naquele momento.

A colocação acima pode sugerir uma tendência para amenizar a responsabilidade individual em prol do coletivo social, que poderia ser mais bem trabalhada.

Com relação à dúvida sobre a aula da Dra. Zara, a coordenação interpreta que a controvérsia 
se deve ao fato de o assunto - Direitos e Deveres - gerar incômodo a todos.

(Participou: Graciela Pagliaro).

\section{CONSIDERAÇÕES GERAIS E OUTRAS SU- GESTÕES}

Acrescentamos ainda algumas considerações finais:

\section{$1^{\circ}$ Quanto ao Programa:}

Os objetivos e o trabalho sócio-educativo realizado são de indiscutível relevância social. A estratégia de atuar junto aos pais, visando a garantia dos direitos de filhos menores, abrindo-se espaço para a informação, orientação, sensibilização, expressão e participação, é vista como uma alternativa valiosa para gerar a almejada transformação. É promissora, não só pela adequação do trabalho à população envolvida, como pelo cuidado em articulá-lo com outros projetos paralelos que o complementam e reforçam em seus objetivos, como por exemplo a Família Solidária e a criação da Cooperativa. Cremos que, enquanto processo, é importante seu acompanhamento e a avaliação de egressos, em termos de resultados sustentados (reinserção social, convivio da criança junto à família, freqüência à escola). Um exemplo vivo de sucesso do trabalho foi a presença de Cristiane (egressa do $1^{\circ}$ Curso da Escola de Pais), sua história de vida e seu crescimento pessoal. Ressalta-se ainda o suporte oferecido com a criação de estratégias para garantir a freqüência dos alunos ao curso, como disponibilidade de creche, cesta básica, e vale transporte. Certamente, tratase de modelo a ser multiplicado.

\section{$2^{\circ}$ Quanto à carga horária e período:}

Considerando-se a realidade de vida das pessoas e suas necessidades de trabalho, a carga horária e o periodo parecem adequados, levandose em conta a possibilidade de abertura de novas turmas.

\section{$3^{\circ}$ Quanto ao conteúdo:}

Os temas foram bem selecionados e abordam questões importantes. No entanto, em se tratando da dinâmica das relações familiares com toda a gama de necessidades e dificuldades, e em condições desvantajosas de vida, há uma grande variedade de assuntos importantes possíveis, donde as sugestões apresentadas adiante, que certamente dependerão dos recursos e do tempo disponíveis para trabalhá-las. Sentiu-se falta da discussão sobre paternidade responsável e recursos para o planejamento fami- liar prevista no programa inicial, porém não realizada durante o período, entendendo-se ser o tema de especial importância para o grupo em questão. Outra discussão a aprofundar, refere-se aos papéis do pai e da mãe, considerando-se os condicionantes biológicos, sócio-culturais e econômicos.

\section{$4^{\circ}$ Quanto à metodologia:}

Apoia-se em atividades de grupo e estímulo à participação de todos, com espaço para que os participantes também direcionem os trabalhos, com seus depoimentos e questões. Foi criado um clima de descontração e uma atmosfera afetuosa que favoreceram a participação. Os filmes projetados foram muito ricos em situações de vida, e familiares à camada social dos participantes, porém nem sempre adequadamente trabalhados, como no primeiro deles. Jogo, música, atividade manual e massagem foram outros procedimentos utilizados.

\section{$5^{\circ}$ Quanto à Coordenação}

Foi considerada eficiente, competente, segura e comprometida; com atitude respeitosa, prestimosa, sem assistencialismo e estimuladora da autonomia dos participantes com relação à cidadania.

\section{$6^{\circ}$ Quanto à participação da UIPES/ORLA-BR}

Reconhecendo a indiscutível relevância do trabalho, o objetivo do grupo de profissionais da UIPES/ORLA-BR foi observar, conhecer o trabalho, inserir-se no contexto, aprender, integrarse, analisar. Pensa-se numa forma de discutir com a equipe de profissionais do NEP o conceito de saúde e a proposta de Promoção da Saúde (conceito de empoderamento, disponibilização de informações sobre saúde, articulação com outros profissionais, etc.). Uma futura contribuição prática poderá ser considerada ou sugerida por ambas as partes. NEP:

Em síntese, propõe-se à consideração do

- a realização de reunião entre a coordenação do NEP e a equipe da UIPES/ ORLABR para a troca de informações complementares e percepçoe s, incluindo os objetivos gerais e o trabalho da União Internacional de Promoção da Saúde e Educação para a Saúde (UIPES), com ênfase no conceito atual de Promoção da Saúde;

- a realização de uma ou mais oficinas de educação em saúde/promoção da saúde com os participantes da Escola de Pais, em oportunidade futura; 
- a inclusão de matéria sobre a Escola de Pais no próximo Boletim da UIPES/ ORLA-BR; a elaboração de um estudo sobre o projeto que focalize, por exemplo, o perfil da população de participantes nas distintas turmas, sua procedência (perfil, recursos e deficiências do bairro de origem), histórias de vida, resistências, definição de indicadores dos resultados desejados, mudanças percebidas nos egressos, acesso a oportunidades para a geração de renda, inserção social etc.).

\section{Questões a esclarecer:}

- Como será feito o acompanhamento posterior do grupo nos próximos meses? Quais as atividades? Com qual periodicidade?

- Há indicadores de avaliação definidos?

- Que possibilidades de emprego ou de participação em atividade para geração de renda efetivamente existem para os participantes? De que condições dependem?

- Há acompanhamento dos egressos do programa (com mais de 1 ano de participação na Escola de Pais)?

- Existem casos de maus resultados ou reincidência? Em que proporção?

\section{Sugestões:}

Caso seja possível, em termos de carga horária, sugere-se mais atividades com música, oportunidades de expressão corporal, dança, oficinas de sensibilizarão, jogos interativos.

Quanto à metodologia, propõe-se a realização de dinainica de pequenas grupos, possibilitando a todos se manifestaram e debaterem entre si. Recomenda-se, também, que as reuniões terminem com uma síntese e avaliação feita pelos participantes, de como perceberam e vivenciaram a atividade.
Com relação às atividades manuais, em que pese os limites de tempo, apoio logístico e disponibilidade de se dispor de vários materiais (tecidos, barro, sucata, tintas, etc.), seria interessante a realização de oficinas de artesanato, que permitissem a descoberta de aptidões e novas ocupações, com vistas à eventual profissionalização.

Dentre os conteúdos trabalhados, mereceriam ser aprofundadas, com os participantes, as questões relativas ao SIM e ao NÃO na relação pais e filhos. Por que sim e por que não? E, ainda, a questão da coerência, levando os pais a refletirem sobre o que os motiva a dizer sim ou não (se é o estado emocional da mãe/ pai ou a ação do filho). A paternidade responsável, planejamento familiar e uso correto de contraceptivos são temas vistos como de fundamental importância para o grupo em questão, entendendo-se que o mesmo merece uma atenção prioritária. Sugeriu-se, ainda, a realização de oficina que abordasse a questão da violência dentro da família: fatores determinantes e condicionantes.

Temas na linha da promoção da saúde que podem ser discutidos: conceito de saúde e direitos constitucionais, educação ambiental, aproveitamento de alimentos (ex. do projeto do SESC/ SP, "São Paulo à mesa" - quem tem a comida, folhas, legumes e outros? o que há por perto? quem pode dar/fornecer? como aproveitar? como conservar e distribuir. 1) Neste exemplo, o pontual é o bairro: de que bairro procedem? O que existe neste bairro? Onde procurar os recursos ? Acrescentamos, ainda, a importância da discussão de estratégias de sustentabilidade para a geração de renda.

Outros temas mais específicos de saúde, na medida do interesse dos participantes: problemas respiratórios e digestivos, rehidratação oral, vacinação, verminoses, profilaxia de doenças transmissíveis, saúde bucal, soro caseiro, acompanhamento do crescimento, recursos de atendimento. Junho de 2001; 


\begin{abstract}
In conformity with the Statute of the Child and Adolescent (Estatuto da Crianca e do Adolescente - ECA), article 129, paragraph $\mathrm{I}^{\wedge} \mathrm{V}$, chapter $\mathrm{V}$, which states that the attendance to courses and orientation programs are measures that may be applicable to parents and those in charge of children, the first Court for Childhood and Youth of Rio de Janeiro has been developing the project "School for Parents". This initiative, through social-educational actions for parents, aims at family reintegration of children and adolescents living in social risk conditions. Nine "Schools for Parents" - each with approximately 8 meetings in its first stage - have been implemented since 1998. During these meetings, various education, health and citizenship related topics have been stressed. This procedure has become an opportunity to point out social rights and duties as far as parentschildren relations are concerned. The families received food supply ("food baskets") from the Chil\&ood and Adolescence Foundation (Fundacao da Infancia e Adolescencia - FIA), free transportation tickets, support to keep children in schools or nurseries sponsored by the community or the Court, orientation given by social assistants and psychologists, as well as other benefits, thanks to partnership with institutions, organizations and ente prises, including the private sector. After this first stage, the participants are granted a 12-month support by the program "Family Solidarity", which is funded by people who sponsor one of the families with the equivalent to I minimum salary per month. Support to fnd oppor unities for generating income for the families has been another way of social insertion. This includes integrating the on-going co-operative enterprise of the "School for Parents". The State Secretariat of Social Assistance, the Municipal Secretariat for Social Development and the Tutelary Councils have been involved in the program, ensuring the progress of this work beyond the Court rooms and reaching the families in their home places.
\end{abstract}

Key-words: School for Parents; Court for Childhood and Youth; infractor parents; Statute of the Child and Adolescent. 